\title{
Development Of Circular Polarization 5.5 Ghz Microstrip Antenna E-Shaped For Synthetic Aperture Radar Communication
}

\author{
Kunto Aji Wibisono ${ }^{1}$, Riza Alfita ${ }^{1}$, Alfian Nur Rahman, Farohaji Kurniawan ${ }^{2}$, Adi Kurniawan ${ }^{1}$, Deni Laksono $^{1}$ \\ ${ }^{1}$ Electrical Engineering Faculty of Engineering University of Trunojoyo Madura, 69162, Indonesia \\ ${ }^{2}$ Center for Aeronautics Technology, National Institute of Aeronautics and Space, Bogor,16350, Indonesia
}

\begin{abstract}
This paper presents development of circular polarization $5.5 \mathrm{GHz}$ microstrip antenna E-shaped for synthetic aperture radar Communication. Microstrip antenna designed Truncated E-shaped the centered frequency is $5.5 \mathrm{GHz}$ and bandwidth that is wide $200 \mathrm{Mhz}$ for Synthetic Aperture Radar communication. The proposed antenna on $1.6 \mathrm{~mm}$ thickness of FR-4 substrate with the dielectric constant 4.6. The best simulated result can achieve -10dB reflection coefficient bandwidth $600 \mathrm{Mhz}$, VSWR 1,578, gain 5,67 dbiC and axial ratio 2,947 with left-handed circular polarization. The best measurement result can achieve $-10 \mathrm{~dB}$ reflection coefficient bandwidth $951 \mathrm{MHz}$ (5.304-6.255), VSWR 1,25, gain 6,17 dBiC with left-handed circular polarization.
\end{abstract}

Keywords: Circular Polarization, Radar Communication, Microstrip Antenna

\section{Introduction}

Technology in microstrip antennas is currently many used because of its size and shape, it is light in weight, easy to integrate into suitable telecommunication devices and easy fabrication [1] - [4]. Synthetic aperture radar system can operate in various conditions and weather [5] - [7]. In general, the C-band frequency (4$8 \mathrm{GHz}$ ) for research is widely used as communication [8], [9]. In general, SAR is used as a sensor for mapping and its use is in uav, airplanes, satellites and others [5][7],[10] - [19]. The material used in this antenna is FR4 , because this material is cheap and easy to fabricate [20]. This study uses circular polarization because circular polarization in uncertain weather conditions is better than linear polarization [8].

Circular polarization in microstrip antennas is widely used in mapping, communication and so on. Microstrip antenna is very popular used wirelessly [21]. The design for this microstrip antenna is E-shaped with a truncated corner. For provisions, the center frequency is at 5.5 $\mathrm{GHz}$, bandwidth is $200 \mathrm{MHz}$, return loss is $-10 \mathrm{~dB}$, axial ratio is $3 \mathrm{~dB}, 1$ VSWR 2 and uses circular polarization.

\section{Design and Configuration}

There are several stages carried out to carry out the research as shown in Figure 1. In the first stage, namely determining the specifications on the microstrip antenna. The second stage is to calculate the design of the microstrip antenna. The third stage is Simulating the antenna using the CST Studio Suite 2019 software. The fourth stage is fabricating the appropriate antenna. The fifth stage is simulating the fabrication of the antenna in the anechoic chamber.

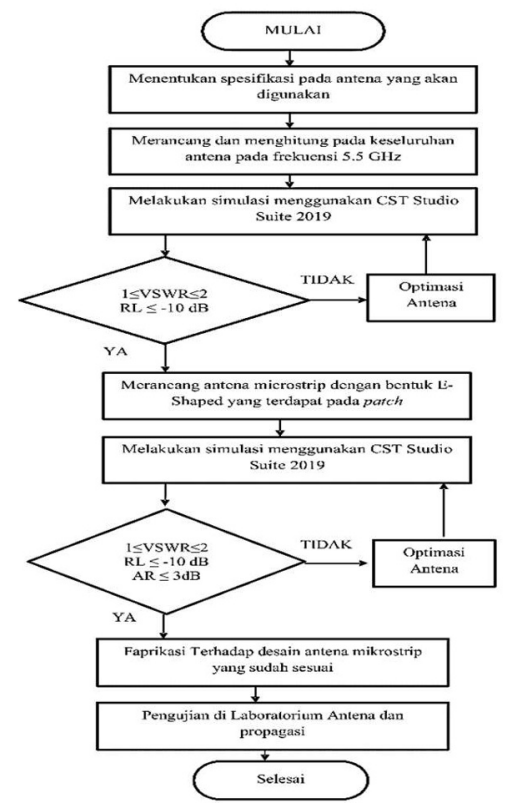

Fig. 1. Flowchart 
The detail configuration is shown in figure 2. The antenna is designed with two substrate-of dielectric constant, the top of the substrate is a patch that can later electro magnetic waves.
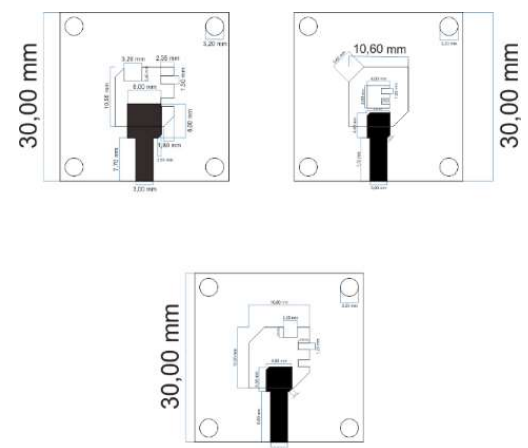

Fig. 2. Design microstrip antenna

Below the top substrate there is a feed line which serves as a liaison for electromagnetic waves from the power supply to the patch. The backside second layer set a ground plane. Material substrate used FR-4 with 4.6 dielectric constant, $1.6 \mathrm{~mm}$ thickness and total thickness $3.2 \mathrm{~mm}$. Material patch antenna used copper with 0.035 mm thickness.

The patch of antenna is formed truncated corner with E-Shaped from rectangular patch aims as make circular polarization. Length at the cutting angle of the patch is $1.8 \mathrm{~mm}$. The top hole is used to increase width of antenna bandwidth and aims as make circular polarization.

The following is a table of calculation results at three design microstrip antenna.

Table 1 calculation result

\begin{tabular}{|l|l|l|l|}
\hline \multicolumn{3}{|c|}{ Nilai (mm) } & \multirow{2}{*}{ Keterangan } \\
\hline 1 & 2 & 3 & $\begin{array}{l}\text { Ground and substrate } \\
\text { length and width }\end{array}$ \\
\hline 30 & 30 & 30 & Thickness patch \\
\hline 0.035 & 0.035 & 0.035 & Thickness subsrat \\
\hline 1.6 & 1.6 & 1.6 & $\begin{array}{l}\text { Total thickness double } \\
\text { subsrat }\end{array}$ \\
\hline 3.2 & 3.2 & 3.2 & Length patch \\
\hline 10.5 & 10.8 & 10.6 & Width Patch \\
\hline 10.5 & 10.8 & 10.6 & Width feedline (1) \\
\hline 3 & 3 & 3 & Length feedline (1) \\
\hline 7.7 & 9 & 9 & Width slot E-Shape \\
\hline 2.5 & 2.1 & 4 & Length slot E-Shape \\
\hline 1.5 & 1.2 & 4 & $\begin{array}{l}\text { Width top slot / lebar } \\
\text { rectangular slot (3) }\end{array}$ \\
\hline 3.2 & 2.5 & 1.5 width \\
\hline 2.6 & 2 & 1 & $\begin{array}{l}\text { Length top slot / watang slot (3) } \\
\text { rectangular }\end{array}$ \\
\hline 4 & 4 & 4 & side shape \\
\hline 1.8 & 2.8 & 2.6 & $\begin{array}{l}\text { Size on side truncated } \\
\text { corner (1) }\end{array}$ \\
\hline 6 & 4.5 & 4 & Width feedline (2) \\
\hline 6 & 4.3 & 4.2 & Length feedline (3) \\
\hline 0.6 & 0.5 & 0.5 & $\begin{array}{l}\text { Size on side truncated } \\
\text { corner (2) }\end{array}$ \\
\hline 1.6 & 1.6 & 1.6 & Hole diameter \\
\hline & & & \\
\hline
\end{tabular}

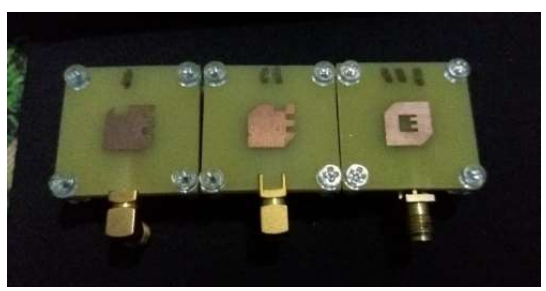

Fig. 3. Fabricated microstrip antenna

This double layer antenna is combined by four plastics screws at each corner. The fabricated antenna with total dimension $30 \mathrm{~mm} \times 30 \mathrm{~mm}$ is shown in figure 3.

\section{Result and Discussion}

The proposed antenna has been done through simulation and measurement. The results tested in this experiment are coefficient reflection, bandwidth, gain, vswr and axial ratio.

\subsection{Simulated}

The following are the results of the 2019 CST Studio Suite simulation in the three designs, which contain the results of return loss, vswr, bandwidth, gain and axial ratio. Each design has a different color design 1 (blue), 2 (green), 3 (red).

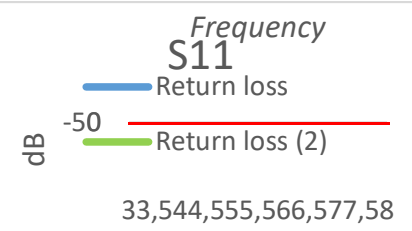

Fig. 4. Return loss and bandwidth

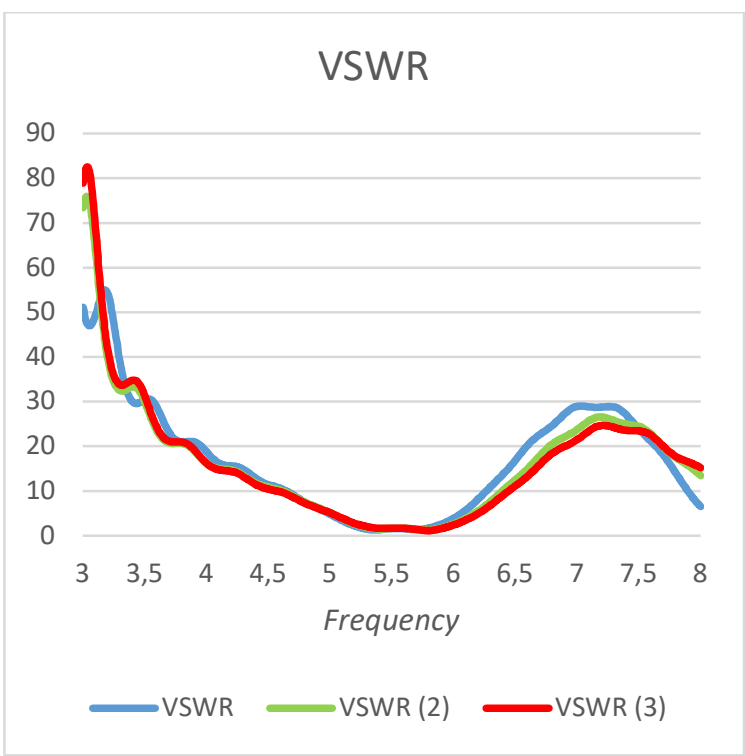

Fig. 5. VSWR 


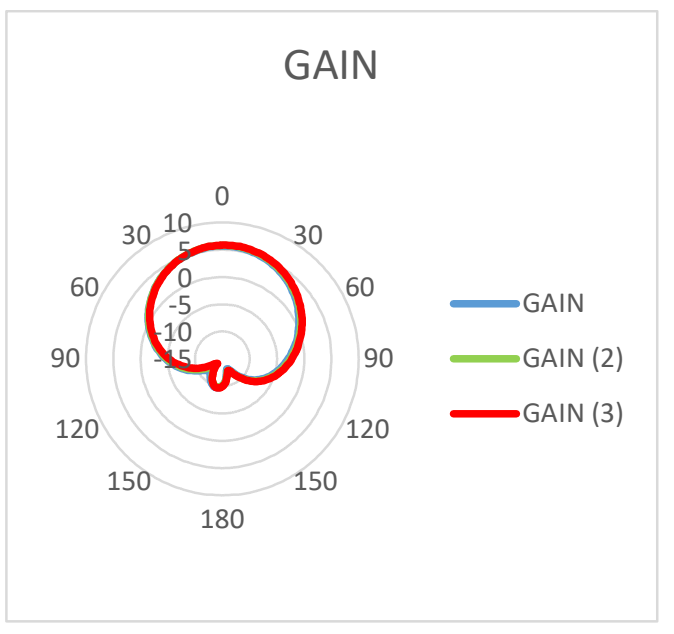

Fig. 6. Gain

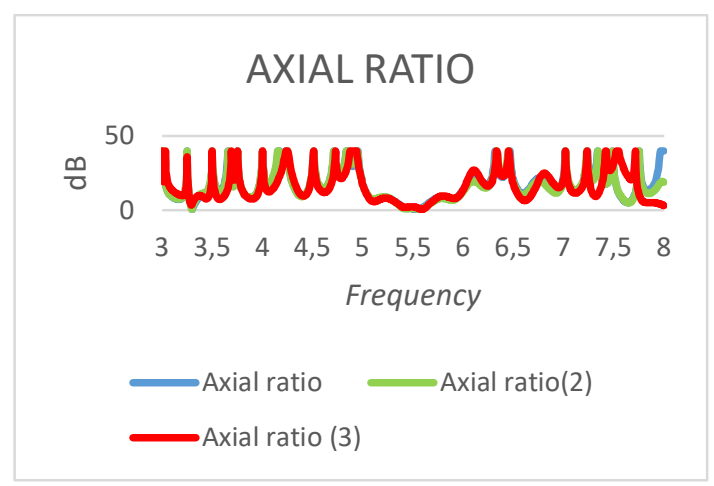

Fig. 7. Axial ratio

The following is a table of simulation results at three design microstrip antenna.

Table 2. Simulation results

\begin{tabular}{|l|l|l|l|l|l|}
\hline Desain & $\begin{array}{c}\text { Return } \\
\text { loss }\end{array}$ & Bandwidth & VSWR & $\begin{array}{l}\text { Axial } \\
\text { Ratio }\end{array}$ & Gain \\
\hline 1 & $\begin{array}{c}-12,978 \\
\mathrm{~dB}\end{array}$ & $600 \mathrm{MHz}$ & 1,578 & $\begin{array}{l}2,947 \\
\mathrm{~dB}\end{array}$ & $\begin{array}{l}5,67 \\
\mathrm{dBiC}\end{array}$ \\
\hline 2 & $\begin{array}{c}-12,671 \\
\mathrm{~dB}\end{array}$ & $\begin{array}{l}639,2 \\
\mathrm{MHz}\end{array}$ & 1,61 & $\begin{array}{l}1,479 \\
\mathrm{~dB}\end{array}$ & $\begin{array}{l}5,82 \\
\mathrm{dBiC}\end{array}$ \\
\hline 3 & $\begin{array}{c}12.203 \\
\mathrm{~dB}\end{array}$ & $639 \mathrm{MHz}$ & 1,65 & $\begin{array}{l}0,901 \\
\mathrm{~dB}\end{array}$ & $\begin{array}{l}5,88 \\
\mathrm{dBiC}\end{array}$ \\
\hline
\end{tabular}

The simulation results that have been carried out in the 2019 cst studio suite show results that are in accordance with the provisions of this research.

\subsection{Measurements}

At this time the measurements were carried out in the anechoic chamber at the LAPAN satellite technology center. The measurement proces this time produces results that are quite different from the simulation in the cst studio suite. The following is the result of the measurement process in the anechoic chamber.

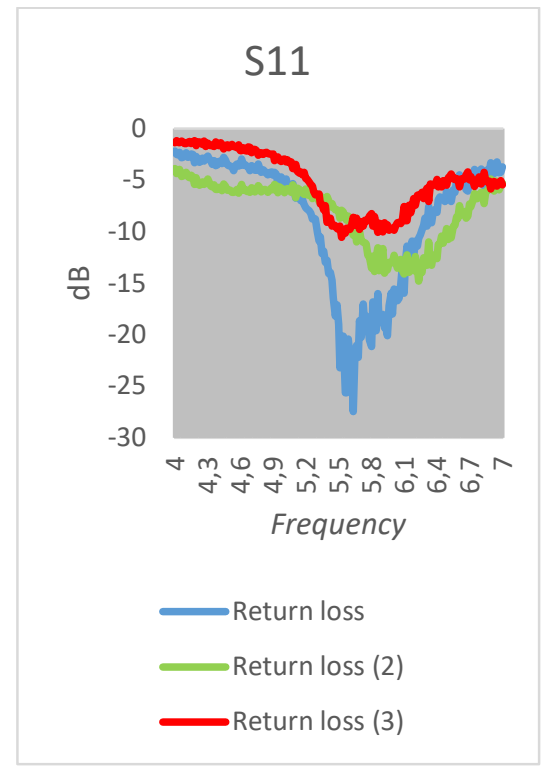

Fig. 8. Return loss and bandwidth (measurements)

This result is a different result than that done in the simulation cst studio suite. For design 1 the results are better and also for the width range is wider than in the simulation. In the second design the results are shifted than in the simulation. In the third design, the results do not match what was done in the simulation. For bandwidth, it can be seen from the results of return loss with a wide range of frequencies in the first design resulting in $951 \mathrm{MHz}$, this result is better than that done in the simulation. For the second design, which produces $915 \mathrm{MHz}$, this result is in accordance with the provisions, but this result is shifted from the simulation. For the third design to produce $7 \mathrm{MHz}$ this result is not in accordance with the provisions and also different from the results in the simulation.

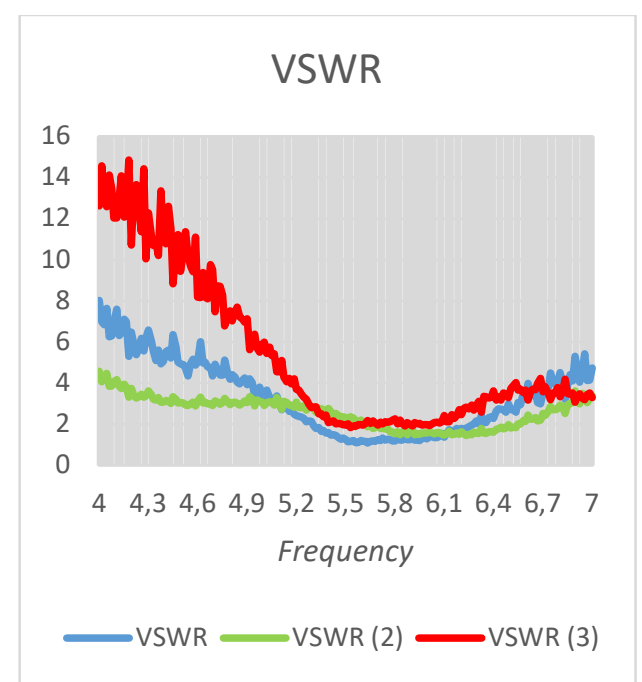

Fig. 8. VSWR

VSWR (Voltage Stage Wave Ratio) results are different for each design with a center frequency of 5.5 GHz. The first design produces 1.25 , this result is in accordance with the provisions and is better than the 
simulation. In the second design the results of 2.34 are not in accordance with the provisions due to the shift in the results of the measurement. The third design produces a value of 1.97 , this result is appropriate and not better than in the simulation.

There are Gain results in the first design that are in accordance with the provisions of return loss, vswr and bandwidth. This gain focuses on the center frequency of $5.5 \mathrm{GHz}$. The result of this Gain is $6.17 \mathrm{dBiC}$, this result is also better than what was done in the simulation which produces $5.67 \mathrm{dBiC}$.

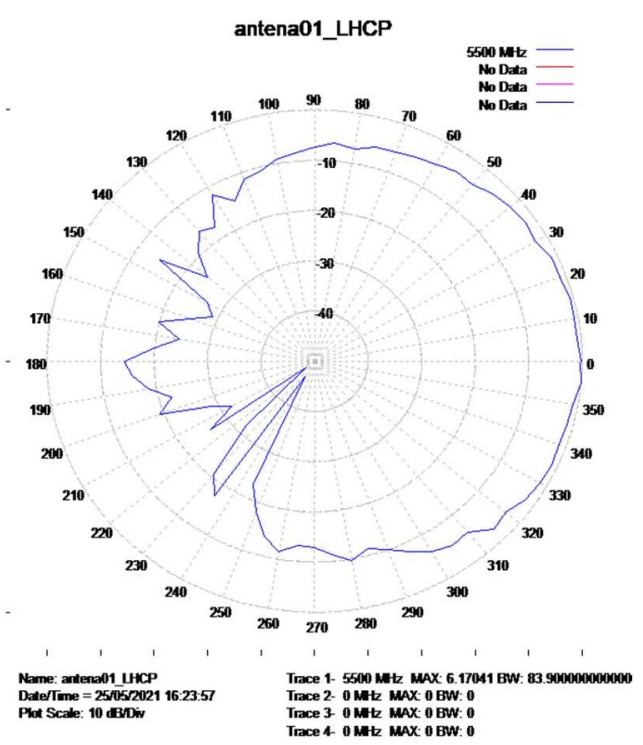

Fig. 9. Gain

\section{Conclusion}

For the analysis that I got from these three designs, the results from the simulation in the cst studio suite software and measurements in the anechoic chamber there are quite a lot of differences. In the first design results for measurement the results are better than the simulation in the cst studio suite. In the second design result for the cst studio simulation the results are better than the measurement, due to the shift in the results in the frequency to the right, because there is a problem in the cavity between the two substrates that is not properly attached. In the third design result for the simulation of cst studio suite the results are better than the measurement, because there are problems in the cavity of the two substrates that are not tightly attached and the SMA connector is different from the two previous designs.

First, I would like to thank my first supervisor, Mr. Riza Alfita, and my second supervisor, Mr. Kunto Aji Wibisono, for the guidance in conducting this research. I would like to thank all the staff and researchers of the avionics laboratory of the Lapan Aviation Technology Center, especially Mr. Farohaji Kurniawan for the knowledge I gained in conducting this research. and I thank all the staff and researchers of the anechoic chamber laboratory at the Lapan Satellite Technology
Center for giving the time to test the equipment in my research.

\section{References}

[1] J. R. James and P. S. Hall, Handbook of Microstrip Antennas. (1989).

[2] J. L. Volakis, Antenna Engineering Handbook, Fourth Edition. (2007).

[3] C. A. Balanis, Modern antenna handbook. 2007.

[4] I. Surjati, S. Alam, and S. Hotman, "Polarisasi Melingkar Antena Mikrostrip E Shape Dengan Pencatu Electromagnetic Coupling," J. Rekayasa Elektr., vol. 13, no. 1, p. 35, (2017), doi: 10.17529/jre.v13i1.6006.

[5] C. E. Santosa, J. T. Sri Sumantyo, C. M. Yam, K. Urata, K. Ito, and S. Gao, "Subarray design for C-band circularly-polarized synthetic aperture radar antenna onboard airborne," Prog. Electromagn. Res., vol. 163, no. August, pp. 107-117, (2018), doi: 10.2528/pier18060602.

[6] F. Kurniawan et al., "A C-band Circular Polarized Antenna with Elliptical Shape for SAR Sensor," Proceeding - 2020 Int. Conf. Radar, Antenna, Microwave, Electron. Telecommun. ICRAMET 2020, pp. 246-248, (2020).

[7] C. E. Santosa, J. T. Sri Sumantyo, K. Urata, C. M. Yam, K. Ito, and S. Gao, "Development of a low profile wide-bandwidth circularly polarized microstrip antenna for C-band airborne CP-SAR sensor," Prog. Electromagn. Res. C, vol. 81, no. January, pp. 77-88, (2018), doi: 10.2528/pierc17110901.

[8] S. Chakraborty, M. A. Hossain, and M. A. Rahman, "Design and Performance Studies of an Elliptical Slot Circular Polarization Antenna for C-Band Wireless Applications," 2nd Int. Conf. Electr. Comput. Commun. Eng. ECCE 2019, pp. 1-6, (2019), doi: 10.1109/ECACE.2019.8679189.

[9] M. M. Lumembang and B. Abdullah, "Rancang Bangun Antena Mikrostrip Model Biquad untuk Komunikasi Wireless dengan Pandu Gelombang Coplanar pada Frekuensi $5.8 \mathrm{GHz}$," Positron, vol. 8, no. 1, p. 27, (2018), doi: 10.26418/positron.v8i1.24050.

[10] L. Zhang, S. Gao, and Q. Luo, "Wideband circularly polarized antennas for satellite communications," 2017 IEEE 6th Asia-Pacific Conf. Antennas Propagation, APCAP 2017 Proceeding, pp. 1-3, (2018), doi: 10.1109/APCAP.2017.8420635.

[11] F. Kurniawan, J. T. S. Sumantyo, and A. Munir, "Wideband LHCP truncated-circular-shape microstrip antenna for SAR application," 2017 IEEE Antennas Propag. Soc. Int. Symp. Proc., vol. 2017-Janua, pp. 2299-2300, (2017), doi: 10.1109/APUSNCURSINRSM.2017.8073192.

[12] C. X. Mao, S. Gao, Y. Wang, Q. X. Chu, and X. $\mathrm{X}$. Yang, "Dual-Band Circularly Polarized Shared-Aperture Array for C-/ X-Band Satellite Communications," IEEE Trans. Antennas 
Propag., vol. 65, no. 10, pp. 5171-5178, (2017), doi: 10.1109/TAP.2017.2740981.

[13] L. Li, H. Wang, L. Liu, X. Shao, Q. Kuang, and J. $\mathrm{Hu}$, "Design of C-Band Low-Profile and Lightweight Spaceborne SAR Antenna," 2018 China Int. SAR Symp. CISS 2018 - Proc., vol. 2, no. May, pp. 12-15, (2018), doi: 10.1109/SARS.2018.8552028.

[14] M. A. Haque, L. C. Paul, R. Azim, M. M. Mowla, A. Saleh, and M. N. Hossain, "A Modified EShaped Microstrip Patch Antenna for C Band Satellite Applications," 2019 IEEE Int. Conf. Signal Process. Information, Commun. Syst. SPICSCON 2019, no. 5, pp. 27-31, (2019), doi: 10.1109/SPICSCON48833.2019.9065126.

[15] P. B. Saha, R. K. Dash, and D. Ghoshal, "Wideband Antenna for C-band Satellite Applications," pp. 262-266, (2020).

[16] F. Kurniawan, J. T. S. Sumantyo, Y. A. Nugroho, G. S. Prabowo, and A. Munir, "A novel technique of broadband circularly polarized microstrip antenna development withsquare ring slot for SAR application," 2018 IEEE Conf. Antenna Meas. Appl. CAMA 2018, pp. 1-3, (2018), doi: 10.1109/CAMA.2018.8530631.

[17] F. Kurniawan, J. T. Sri Sumantyo, K. Ito, H. Kuze, and S. Gao, "Patch antenna using rectangular centre slot and circular ground slot for circularly polarized synthetic aperture radar (CP-SAR) application," Prog. Electromagn. Res., vol. 160, no. November, pp. 51-61, (2017), doi: 10.2528/PIER17082903.

[18] A. M. Yusuf, H. Wijanto, and Edwar, "Dual CX-Band E-Shaped Microstrip Antenna Array $1 \times 8$ for Synthetic Aperture Radar on UAV," Proc. - 2019 IEEE Int. Conf. Signals Syst. ICSigSys 2019, vol. 8, no. 4, pp. 186-189, (2019), doi: 10.1109/ICSIGSYS.2019.8811085.

[19] J. Wang, X. Liang, L. Chen, L. N. Wang, and S. N. Shi, "Joint Wireless Communication and High Resolution SAR Imaging Using Airborne Mimo Radar System," Int. Geosci. Remote Sens. Symp., pp. 2511-2514, (2019), doi: 10.1109/IGARSS.2019.8897826.

[20] D. Dominic and O. Sheeba, "A C-band fabry perot cavity antenna using Fr4 substrate," 2017 Int. Conf. Energy, Commun. Data Anal. Soft Comput. ICECDS 2017, pp. 1921-1924, (2018), doi: 10.1109/ICECDS.2017.8389785.

[21] K. Joni, Haryanto, and S. N. Azizah, "Design Of Modified Microstrip Antenna And 4x1 Microstrip Array For Data Communication At $2.4 \mathrm{GHz}$ Frequency," vol. 1, no. Icst, pp. 532538, (2018), doi: 10.2991/icst-18.2018.111. 